\title{
Safety in Road Tunnels - Safety Target Proposal
}

\author{
Jan Malmtorp ${ }^{1}$, Johan Lundin ${ }^{2}$, Peter Lundman ${ }^{3} \&$ Per Vedin ${ }^{4}$ \\ ${ }^{1}$ Swedish Transport Administration, Solna, Sweden \\ ${ }^{2}$ WSP, Stockholm-Globen, Sweden \\ ${ }^{3}$ AFRY, Borlänge, Sweden \\ ${ }^{4}$ Swedish Transport Administration, Luleå, Sweden \\ Correspondence: Johan Lundin, WSP, Stockholm-Globen, SE-121 88, Sweden. Tel: 46-10-722-8590. E-mail: \\ johan.lundin@wsp.com
}

Received: November 20, 2019; Accepted: December 9, 2019; Published: December 13, 2019

The research is financed by The Swedish Transport Agency and The Swedish Transport Administration (Sponsoring information).

\begin{abstract}
The purpose of this paper is to propose a quantitative target for assessment of life safety in road tunnels and describe how such a target can be utilized and developed further. The target is developed from an analysis of initiating events, accident statistics and analytical approaches and it makes it possible to tailor the safety concept in individual tunnels to meet the target by means of quantitative risk analyses. The results indicate that the practice proposed is beneficial for both quality and transparency in the decision-making, as well as it can be judged to have the potential to improve cost-efficiency in the safety related work. It is concluded that the target should be calibrated and evaluated with data from real tunnels before implementation and that the resulting safety level from present ruling is assessed. Also, it is concluded that the total cost to realize the safety target is assessed. It is recommended to put more effort on general accident prevention in tunnels compared to surface roads in order to reduce the number of events that may escalate beyond control. It is also recommended that the road tunnel safety learning processes are improved by routine collection, compilation and evaluation of data on road tunnel accidents as well as vehicle-fires and dangerous goods accidents in road traffic as a whole.
\end{abstract}

Keywords: road tunnel, safety target, risk analysis, risk management

\section{Introduction}

It is important that road travelling can be conducted at a safe-enough level on all parts of the road system, both on surface roads and in tunnels. However, it is not presently known if that is the case, at least not from a Swedish standpoint. Even if road tunnels, so far, not can be blamed to burden statistics on road traffic accidents, a limited number of accidents do occur on a yearly basis resulting in traffic interruptions, damage on the infrastructure and/or slight to severe personal injuries. These outcomes, however, are not representative of the potential with tunnel accidents and therefore cannot provide the single base for designing road tunnel safety concepts. The potential with road tunnel accidents is better demonstrated by experience from very serious accidents, and which suggest that tunnel risks should be taken very seriously. The lack of data, however, prevents opportunities with empirical learning, analogue to the work on surface road safety, from being seized. Scenarios that may have major consequences but with low or extremely low frequency may not yet have happened and consequently are not covered by experience. This stalls the development of specifications for planning and construction as well as proactive risk management strategies. Presently, processes are not in place to fill this gap in the Swedish regulatory environment.

Historically road tunnels are not explicitly considered within the Swedish Vision Zero Initiative, the long-term ambition with the national road traffic safety work. Instead the Vision is founded on empirical learning from surface roads accident (Tingvall, 1997). Thereby, the Vision's offensive targeting as well as the Safety Indicators in use (such as speed-limit obedience, use of seat-belts etc.) does not reflect the threats from very serious tunnel accidents. This is problematic since the governing rules, laws, regulations and standards do not answer to what extent and how these potentially very serious scenarios should be met, even if the need for analytical risk control 
is realized and risk analyses prescribed for various specific cases. The problem lies with the lack of recommendations or guidelines regarding what risk level that can be accepted, a shortcoming that exposes tunnel design and construction to uncertainties that may lead to tunnels being put into operation with insufficient knowledge of how safe they are. The possibilities to evaluate the utility cost for this unspecified safety will obviously be limited. In fact, due to the complexity of many of the modern tunnel facilities, both the safety level and the cost efficiency of safety measures will be unknown. This leads to decisions on arbitrary bases concerning accident scenarios with a potentially large number of fatalities and safety measures requiring significant resources in terms of investments and operational cost. This may be quite far from the intentions behind the EU-directive regarding minimum safety requirements for tunnels in the Trans-European Road Network (2004/54/EC).

\section{Methods for the Quantification of Safety Targets}

However, there is no safety target or risk evaluation criterion for road tunnels that is "right" or "wrong" (PIARC, 2012). A number of well-established approaches that can be used to determine a safety target are presented in Table 1 (Lundin, 2019) together with brief comments on the applicability for Swedish road tunnels.

Table 1. Possible approaches to setting the level of risk acceptance criteria/safety target.

\begin{tabular}{l|ll}
\hline A & Description of method & Comments \\
acceptance criteria for road tunnels. & $\begin{array}{l}\text { There are no universally accepted risk criteria for road } \\
\text { tunnels (PIARC, 2012). Standards and best practice in } \\
\text { different countries exists, but are embedded in specific } \\
\text { legal, social and cultural environment and is influenced } \\
\text { by many aspects. }\end{array}$ \\
\hline B & $\begin{array}{l}\text { Use current data (accident statistics) for } \\
\text { existing comparable facilities and evaluate } \\
\text { whether the risk acceptance criteria should be } \\
\text { the same as, higher or lower than historical } \\
\text { outcomes. }\end{array}$ & $\begin{array}{l}\text { No sufficiently comprehensive accident statistics are } \\
\text { available that covers accidents characterized by } \\
\text { consequences. However, there are examples of } \\
\text { accidents on the open road that show that various } \\
\text { scenarios with potentially serious consequences can } \\
\text { arise. }\end{array}$ \\
\hline C & $\begin{array}{l}\text { Compare with risk acceptance criteria applied } \\
\text { to other kinds of facilities or activities in other } \\
\text { sectors, in Sweden or internationally. }\end{array}$ & $\begin{array}{l}\text { When making comparison between different types of } \\
\text { risks it is important to consider differences in risk } \\
\text { perception, since the acceptance of risks can vary } \\
\text { significantly depending to the attributes of risks (Slovic, } \\
1997) .\end{array}$ \\
\hline D & $\begin{array}{lll}\text { Compare with the general death rate in the } \\
\text { population (e.g. natural background risks or } \\
\text { risks associated with transportation) and base } \\
\text { acceptance criteria for the facility in question } \\
\text { on this level. }\end{array}$ & $\begin{array}{l}\text { The application of this method as the only basis for } \\
\text { uncertainties in the results are to be avoided. } \\
\text { Comparison with natural background risks is deemed to } \\
\text { be useful provided a plausibility check is performed, } \\
\text { and the chosen levels are discussed. }\end{array}$ \\
\hline E & $\begin{array}{ll}\text { Compare with a similar system or reference } \\
\text { system, i.e. a system proven in use to have an } \\
\text { acceptable safety level and against which the } \\
\text { acceptability of the risks from a system under } \\
\text { assessment can be evaluated by comparison. }\end{array}$ & $\begin{array}{l}\text { differences in how accidents occur and develops in } \\
\text { considered. }\end{array}$ \\
\hline
\end{tabular}

\section{The Idea}

The safety target proposed is built around a comparison of the risk for fatalities in accidents of various magnitudes on surface roads and in road tunnels, based on approach B and E in Table 1. It is founded on statistics and analytical approaches, developed from a list of initiating events.

The proposed target is intended to be used as a tool for decisions on what safety measures may be needed in order to provide a level of life safety in individual road tunnels that equals the safety on surface roads. This paper is based on a research study published by the Swedish Transport Administration (Malmtorp et al. 2014) and gives a 
general overview of the work and extracts the major results and conclusions. The problem with traffic interruptions is not dealt with in the mentioned study. That is, however, studied extensively by Strömgren et al (2014).

The decision tool comprises the performance of quantitative risk analyses for the specific application and where the need for safety measures is identified by comparison with the target. The risk analyses are proposed to be performed as a part of the routine when tunnels are being planned and built but they also are applicable to tunnels in operation. Such methods for risk analyses are well described in the scientific literature, e.g. Integrated Approach to Road Tunnel Safety (PIARC, 2007), Guidance for risk analysis of road tunnels (Norwegian Public Road Administration, 2007), Risk Analysis Methods (Swedish National Board of Building, Housing and Planning, 2005), Risk Analysis for Road Tunnels (PIARC, 2008), and Current Practice for Risk Evaluation for Road Tunnels (PIARC, 2012).

\section{Referring to Surface Road Safety}

There are several motives to use surface road safety as a reference regarding road tunnel safety. Apart from being the obvious choice, it also considers the following:

- It can be deemed politically problematic to aim for different levels of safety in tunnels and on surface roads.

- It recognizes that present road traffic is performed at an acceptable level of safety and that traffic safety will improve in the future.

- It makes road tunnel risk communication more nuanced and transparent since it provides means to discuss both safety levels and safety measures simultaneously.

- It facilitates putting priorities to funding of competing interests since it increases the knowledge of the correlation between the cost for safety measures and safety effect.

The thought of an equivalent safety level in tunnels and on surface roads is not new. It has, for instance, earlier been proposed by PIARC (2011) and the Swedish National Road Administration (2004). This paper revitalizes this thought by presenting a way to measure and verify safety in road tunnels.

\section{Initiating Events}

In order to compare risks in road tunnels and on surface roads it is necessary to identify a common basis for comparison. This has been defined as the accidents that result in fatalities, the initiating events. From the national Swedish road accident database STRADA (Swedish Traffic Accident Data Acquisition) it can be learned that the initiating events in road traffic comprise the following:

- Single vehicle accidents

- Collisions

It may be noted that the concept of initiating events refers to the original accident cause. By example, single vehicle accidents and collisions that result in fires are seen as single vehicle accidents and collisions, but with the twist that they also result in fires. The accident type fire therefore only refers to the situation when fire is the initiating event. The same logic is also used with dangerous goods accidents. The following two types therefore also may be identified:

- Fires

- Dangerous goods accidents

There are no lost lives to be found in STRADA from either fires or dangerous goods accidents, neither on surface roads nor in tunnels. It is however known from international experience that they may cause deaths, particularly in tunnels.

\section{Surface Road Traffic Safety}

It was deemed that accident data from ten consecutive, recent, years was needed to achieve a reasonable solid statistical basis to characterize the modern surface road safety standard. It was also decided to restrict the data to accidents resulting in fatalities. In the end, only the national accident data basis STRADA was judged to provide the necessary information since it covers all accidents reported by the police. The years chosen for the study were 2003 - 2012 (Malmtorp et al. 2014).

The accidents identified in the data basis then were catalogued according to initiating event, type of vehicle involved and number of fatalities in each accident. Also, in order to be representative for a reasonable modern road tunnel standard, only accidents involving cars, buses, trucks and motorcycles were included. Mopeds, bicycles, 
tractors, pedestrians and terrain vehicles thereby were excluded, as also accidents involving wild animals. Each of the resulting entities then were summarized per year resulting in the following, see Table 2.

Table 2. The number of accidents resulting in different number of fatalities and from different initiating events (2003-2012).

\begin{tabular}{llllllllll}
\hline Initiating event & \multicolumn{1}{l}{ Number of fatalities } & per & accident & $(\mathbf{2 0 0 3}$ & $\mathbf{2 0 1 2}$ \\
\hline & $\mathbf{1}$ & $\mathbf{2}$ & $\mathbf{3}$ & $\mathbf{4}$ & $\mathbf{5}$ & $\mathbf{6}$ & $\mathbf{7}$ & $\mathbf{8}$ & $\mathbf{9}$ \\
Single vehicle accidents & 1383 & 77 & 7 & 1 & 0 & 1 & 0 & 0 & 1 \\
Collisions & 1245 & 148 & 28 & 4 & 6 & 1 & 0 & 0 & 0 \\
Fires & 0 & 0 & 0 & 0 & 0 & 0 & 0 & 0 & 0 \\
Dangerous goods accidents & 0 & 0 & 0 & 0 & 0 & 0 & 0 & 0 & 0 \\
Sum & $\mathbf{2 6 2 8}$ & $\mathbf{2 2 5}$ & $\mathbf{3 5}$ & $\mathbf{5}$ & $\mathbf{6}$ & $\mathbf{2}$ & $\mathbf{0}$ & $\mathbf{0}$ & $\mathbf{1}$ \\
Annual average & $\mathbf{2 6 2 , 8}$ & $\mathbf{2 2 , 5}$ & $\mathbf{3 , 5}$ & $\mathbf{0 , 5}$ & $\mathbf{0 , 6}$ & $\mathbf{0 , 2}$ & $\mathbf{0}$ & $\mathbf{0}$ & $\mathbf{0 , 1}$ \\
\hline
\end{tabular}

In order to convert the annual accident averages into more calculable frequencies it was then deemed necessary to consider the amount of travelling needed to produce the accidents in question. A compilation of the relevant mileage was found in "Information about the vehicle mileage per year by Swedish-registered cars, lorries, buses and motorcycles in a year" (Transport Analysis, 2019) and could be noted to vary between 71000 and 77000 million vehicle kilometres during 2003 - 2012. The mean value, 75262 million vehicle kilometres, thereby was used to calculate the number of accidents per million vehicle kilometres, see Table 3 .

Table 3. The frequency of accidents resulting in different number of fatalities $(\mathrm{N})$ per year and million vehicle kilometres.

\begin{tabular}{ccccccccc}
\hline $\mathbf{N}=\mathbf{1}$ & $\mathbf{N}=\mathbf{2}$ & $\mathbf{N}=\mathbf{3}$ & $\mathbf{N}=\mathbf{4}$ & $\mathbf{N}=\mathbf{5}$ & $\mathbf{N}=\mathbf{6}$ & $\mathbf{N}=\mathbf{7}$ & $\mathbf{N}=\mathbf{8}$ & $\mathbf{N}=\mathbf{9}$ \\
\hline $3,5 \mathrm{E}-03$ & $3,0 \mathrm{E}-04$ & $4,7 \mathrm{E}-05$ & $6,6 \mathrm{E}-06$ & $8,0 \mathrm{E}-06$ & $2,7 \mathrm{E}-06$ & $0,0 \mathrm{E}+00$ & $0,0 \mathrm{E}+00$ & $1,3 \mathrm{E}-06$ \\
\hline
\end{tabular}

If the resulting frequencies are presented as an $\mathrm{F} / \mathrm{N}$-diagram, a graphic representation of the correlation between frequencies and accident magnitudes for surface road traffic is achieved, see Figure 1.

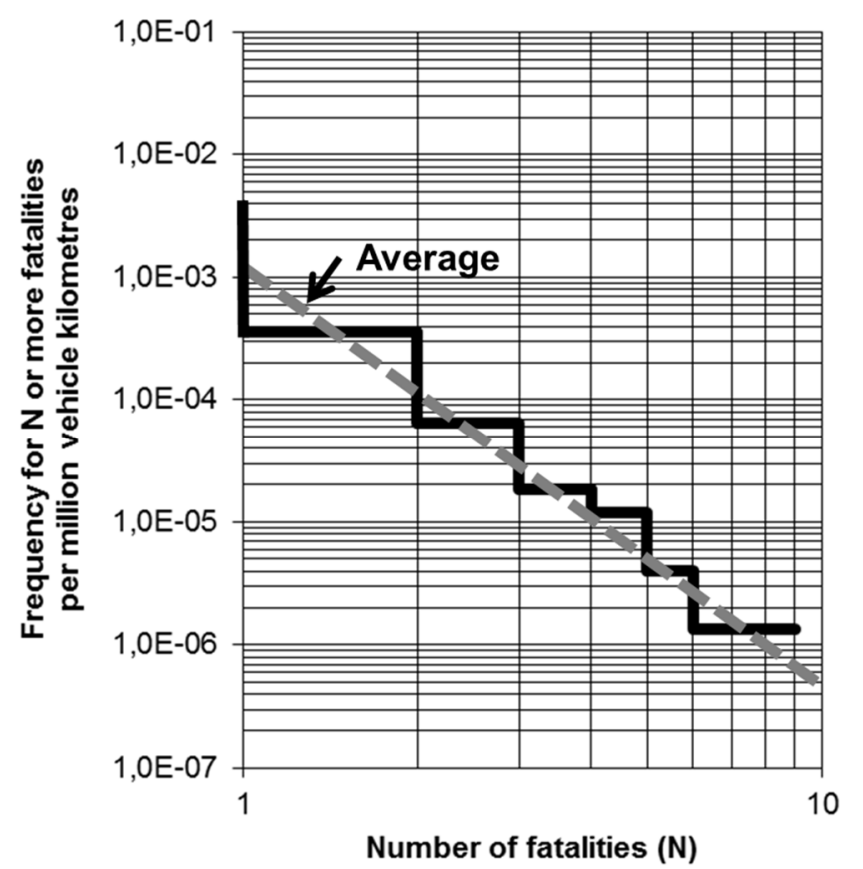

Figure 1. Accident frequencies and magnitudes in surface road traffic displayed in an F/N-diagram (2003 2012). The scaling of both axes is logarithmic. 
The frequencies are expressed as $\mathrm{N}$ or more fatalities per million vehicle kilometres. The consequences are expressed as Number of fatalities, N. It may be noted that both the size of the total risk (the area under the graph) as well as the various combinations of frequencies and consequences, reflect the status of the Vision Zero Initiative work for the period studied. The area also expresses the size of the total societal risk from road traffic accidents, i.e. the average risk in terms of expected number of fatalities per year.

\section{Road Tunnel Safety}

There are no official statistics on road tunnel accidents in Sweden. A separate study based on data from STRADA thereby was compiled in order to get some idea of the number of them and their consequences (Malmtorp et al. 2014). The result indicates that it occurs about $3-4$ accidents per year resulting in severe personal injuries and about 45 per year resulting in slight personal injuries (2003 - 2012). An injury is considered severe if it involves fractures, crush-injuries, lacerations, brain damage or internal injuries or is expected to lead hospitalization. An injury is considered slight if it is not classified as severe. Obviously, road tunnel accidents do occur in Sweden. For comparison, something like 3000 accidents per year resulting in severe personal injuries and 15000 resulting in slight personal injuries occurred during the same period on the surface road network (The Swedish Transport Agency, 2019). These different outcomes can be explained by the different vehicle mileage performed in road tunnels and on the surface roads respectively. Seen from the perspective of accidents per vehicle mileage it thereby was judged that:

- Accident frequencies in road tunnels can be appreciated to be the same as on surface roads if it is expressed per vehicle kilometre, all other parts considered equal.

The above also presupposes tunnels to be viewed as roads through "holes in the ground", i.e. they do not contain any tunnel specific safety measures, at least not more than the regular surface road.

Regarding accident consequences, there were no fatal accidents identified in the road tunnel accident data. It can, however, be seen from international experience that very serious road tunnel accidents can happen and that they have the potential to be more serious than the corresponding accidents on surface roads, see Table 4 .

Table 4. Examples of major road tunnel accidents in Europe (Malmtorp et al. 2014).

\begin{tabular}{lllll}
\hline Year & Tunnel & Length & Consequence & Initiating event \\
1999 & Mont Blanc & ca $11,6 \mathrm{~km}$ & 39 fatalities & Fire \\
1999 & Tauern & ca $6,4 \mathrm{~km}$ & 12 fatalities & Collision (and fire) \\
2001 & St. Gotthard & ca $16,9 \mathrm{~km}$ & 11 fatalities & Collision (and fire) \\
2006 & Viamala & ca $750 \mathrm{~m}$ & 9 fatalities & Collision (and fire) \\
2012 & Sierre & ca $2,5 \mathrm{~km}$ & 28 fatalities & Single vehicle accident \\
\hline
\end{tabular}

The occurrence of tunnel accidents in Sweden demonstrates that there is a real threat from road tunnel accidents. Table 4 demonstrates that this threat also can result in very serious consequences, even if the likelihood is small. Thereby it can be stated that:

- Accident consequences in road tunnels can be appreciated to be more serious than with the corresponding accidents on surface roads, especially if they involve fire or dangerous goods.

If the reasoning above regarding similarities and differences with road tunnel and surface road accidents is applied to the risk profile outlined in Figure 1, the relatively unknown risk profile of road tunnels can be related to the more familiar risks of surface roads. Thereby, the following diagram can be constructed see Figure 2. 


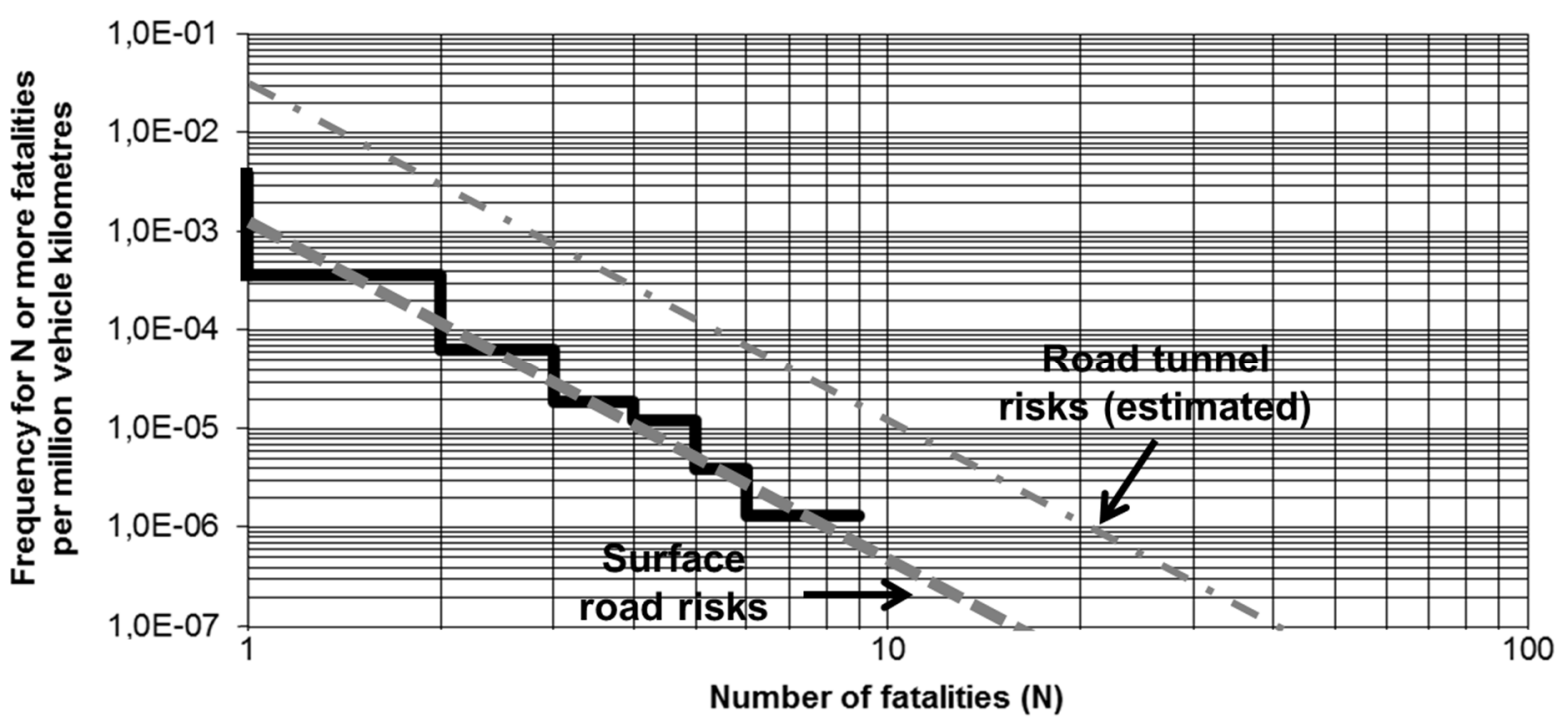

Figure 2. F/N-diagram exposing the estimated difference between the surface road traffic risk profile and the road tunnel risk profile. Both refer to the studied period $2003-2012$.

It is indicated in the figure that the road tunnel risk profile is positioned to the right of the surface road risk profile. This signals a higher total risk in tunnels compared to surface roads, all other parts equal. The more precise size of this difference is, however, uncertain since the magnitude of the potentially worst case is not known. The Mont Blanc road tunnel accident indicates that it may be at least 30 - 40 fatalities. Accordingly, in the diagram, the scale of the consequence axis has been extended.

In order to get an indication of how serious the threats from these very serious scenarios may presently be, data from the Swedish Contingencies Agency's database IDA (Indicator Data Analysis) has been analysed for the period 2010 - 2012 (Malmtorp et al., 2014). The focus was directed towards fires and accidents with dangerous goods.

On a yearly basis, Swedish rescue services are called out to about 4000 fires in various kinds of vehicles. A majority of these, about $85 \%$, involve private cars and the rest involve buses, trucks and caravans. The data are, however, flawed since it also includes arson, fires in garages etc., at least if the number of vehicle-fires that occur in the traffic is to be appreciated. Therefore the data was manually searched for precisely these scenarios. The result indicated that it occurs about 650 fires per year in vehicles that are out and moving in the traffic, signalling a measurable risk of a fire in a tunnel. Real events also confirm that this happen. Also, fires can occur from singlevehicle accidents and collisions. Further data-analysis (IDA) indicates that this happens about 25 times per year (2003 - 2012). So far, however, no serious accidents with vehicle-fires in road tunnels have occurred in Sweden. Apart from fire, also accidents with dangerous goods can result in very serious consequences if they occur in tunnels. Therefore, a similar search as with vehicle-fires was performed (Malmtorp et al. 2014). The data extracted from IDA thereby indicated that rescue services performed about 30 operations per year motivated by threats from accidents with dangerous goods out in the road traffic between the years 2010 - 2012. As with fires in vehicles, this signals a real threat. No serious accidents, however, involving dangerous goods in Swedish road tunnels yet have occurred.

According to the above, the dangers with fires and accidents with dangerous goods in tunnels can be considered to be real also in Sweden. Also, considering the number of people that may get involved in an accident if it occurs on a city highway in a tunnel at rush hour, it must be concluded that it is important to pay attention to accident prevention. In order to appreciate the weight of this threat and identify the best way to manage it, analytic risk assessment may prove critical. However, neither fire in vehicles or accidents with dangerous goods is presently a priority within the Vision Zero Initiative work. From a surface road safety perspective that is the natural choice. From a road tunnel safety perspective it is less so. It may even be seen as a choice that threatens the Vision Zero Initiative itself since it may only take one unfortunate tunnel accident to inflate the national safety target for one year beyond repair. 


\section{A Road Tunnel Safety Target Proposal}

There are several options to choose from in order to transform the estimated road tunnel risk to the size of surface roads. It can be achieved either by reducing frequencies or reducing consequences for the various initiating events, or by various combinations of this. The most feasible way, however, can be appreciated to be reduction of the frequencies for the least serious accidents. This saves lives by reducing the number of accidents where people get injured or killed and it also reduces the number of potential worst-case scenarios, i.e. accidents that can escalate beyond control. In practice that involves frequency reduction for single-vehicle accidents, collisions, fires and dangerous goods accidents. The opposite choice can, as a strategy, be appreciated to be less feasible since it focuses on scenarios that, per definition, are beyond control. Therefore it may be critical in road tunnel safety management to value the possibilities to stay in control. Safety measures like separate lanes, stricter control of speed and less tolerance with car overtaking etc. may be seen as the appropriate, strategic, answer. Also, this may be coupled to an agenda to reduce the likelihood for vehicle-fires and dangerous goods accidents in road traffic in general. Even if this may not be news, the practice with a safety target and the systematic risk analyses offers the possibility to judge when safety may be satisfactory. If it is, the tunnel may be built. If not, complementing measures have to be evaluated in a revised risk analysis until the target is met.

The above reasoning may be reflected in the F/N diagram in Figure 2 by sliding the high-frequency end of the tunnel risk profile downwards along the frequency axis until the resulting area under the risk profile equals the area under the surface road risk profile. The frequency of the least frequent accidents, however, is not tampered with (the worst-case scenarios). The resulting, less inclined, road tunnel risk profile provides a graphic view of what it takes to achieve a total risk in road tunnels that equals the total risk on surface roads. See Figure 3.

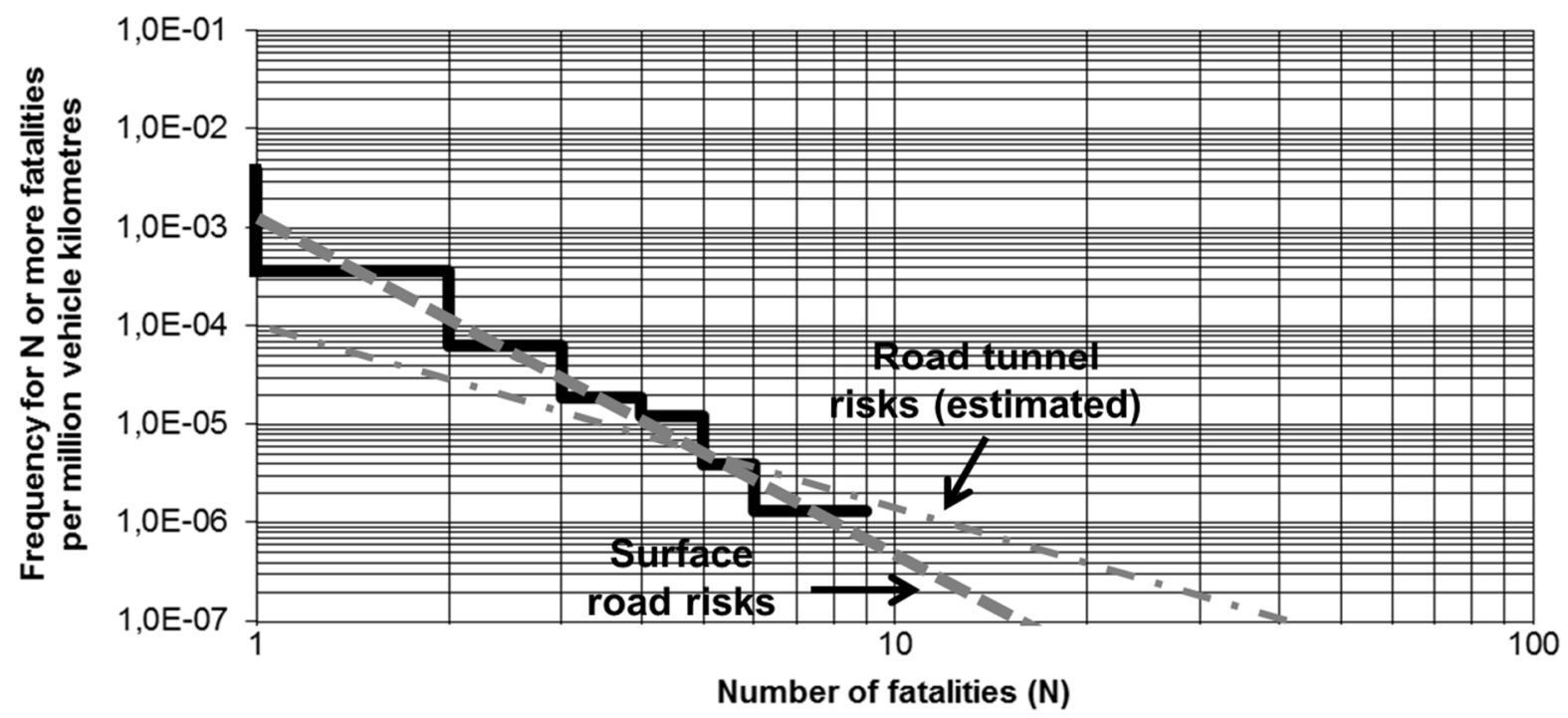

Figure 3. The estimated road tunnel risk profile in Figure 2 has been tilted in order to achieve a total risk which equals that of surface roads.

The produced, less inclined, risk profile can be seen as the minimum level of safety acceptable in road tunnels in order to be equal to surface road safety. If also a second risk profile is placed in the diagram, below and parallel to the first, less inclined, profile an area with even less total risk can be outlined. This even higher level of safety, together with the original, forms an inclined area in the diagram that defines what may be named the ALARP area. In risk analytic practice this spells "As-Low-As-Reasonably-Practicable" and it defines the upper and lower limits for acceptable safety (The Swedish Rescue Services Agency, 1997). It is positioned below the original estimate according to the recommendations in proposed in "Evaluation of risk" (The Swedish Rescue Services Agency, 1997), mainly to compensate for uncertainties. See Figure 4. 


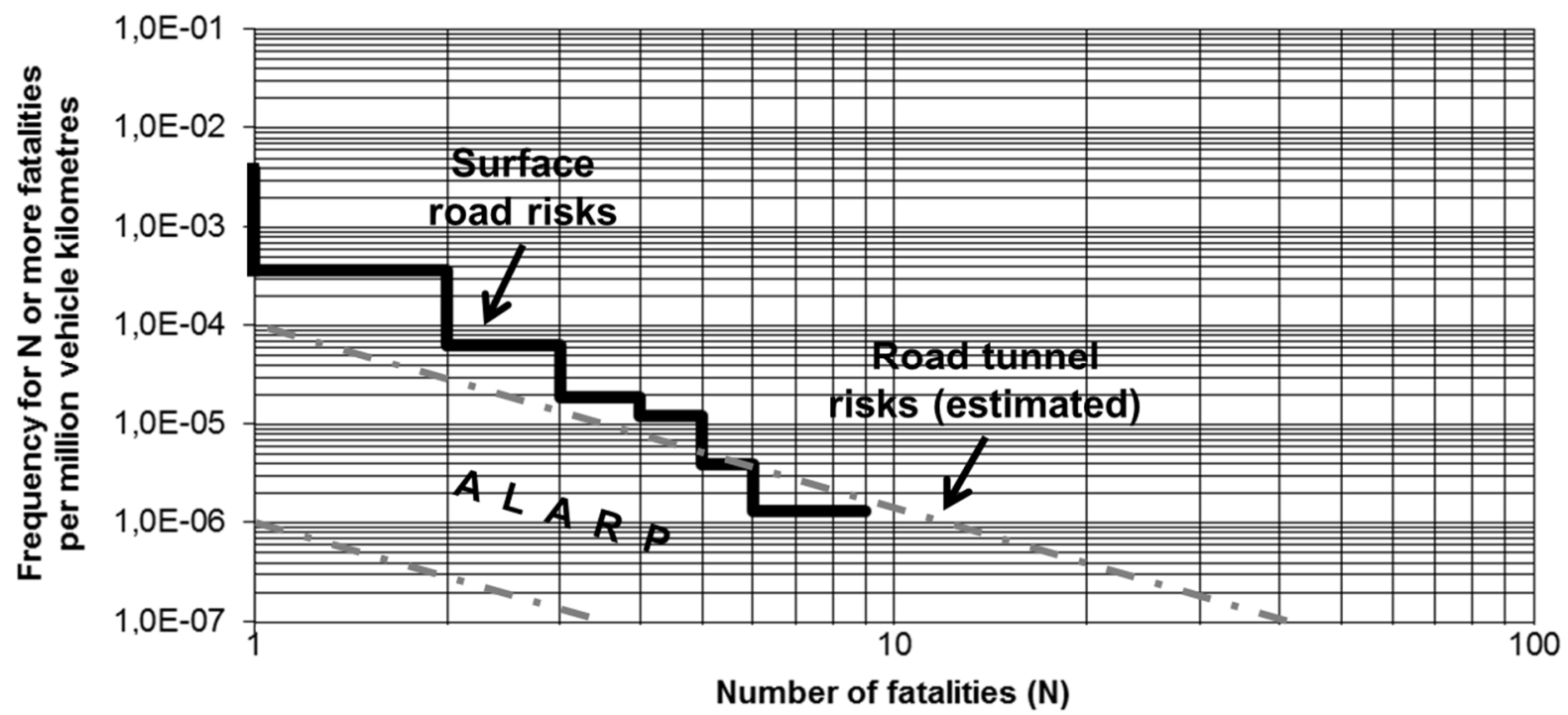

Figure 4. Upper and lower limits for acceptable safety in road tunnels compared to the risk in surface road traffic (2003 - 2012).

The ALARP area also composes the risk policy. By example, it defines which combinations of frequencies and consequences that can be allowed in order to achieve the safety target and which cannot be allowed. Above and to the right of the ALARP area the risk is considered to be high. Below and to the left of the ALARP area the risk is considered to be low. The following safety target for road tunnels thereby may be proposed, see Figure 5 .

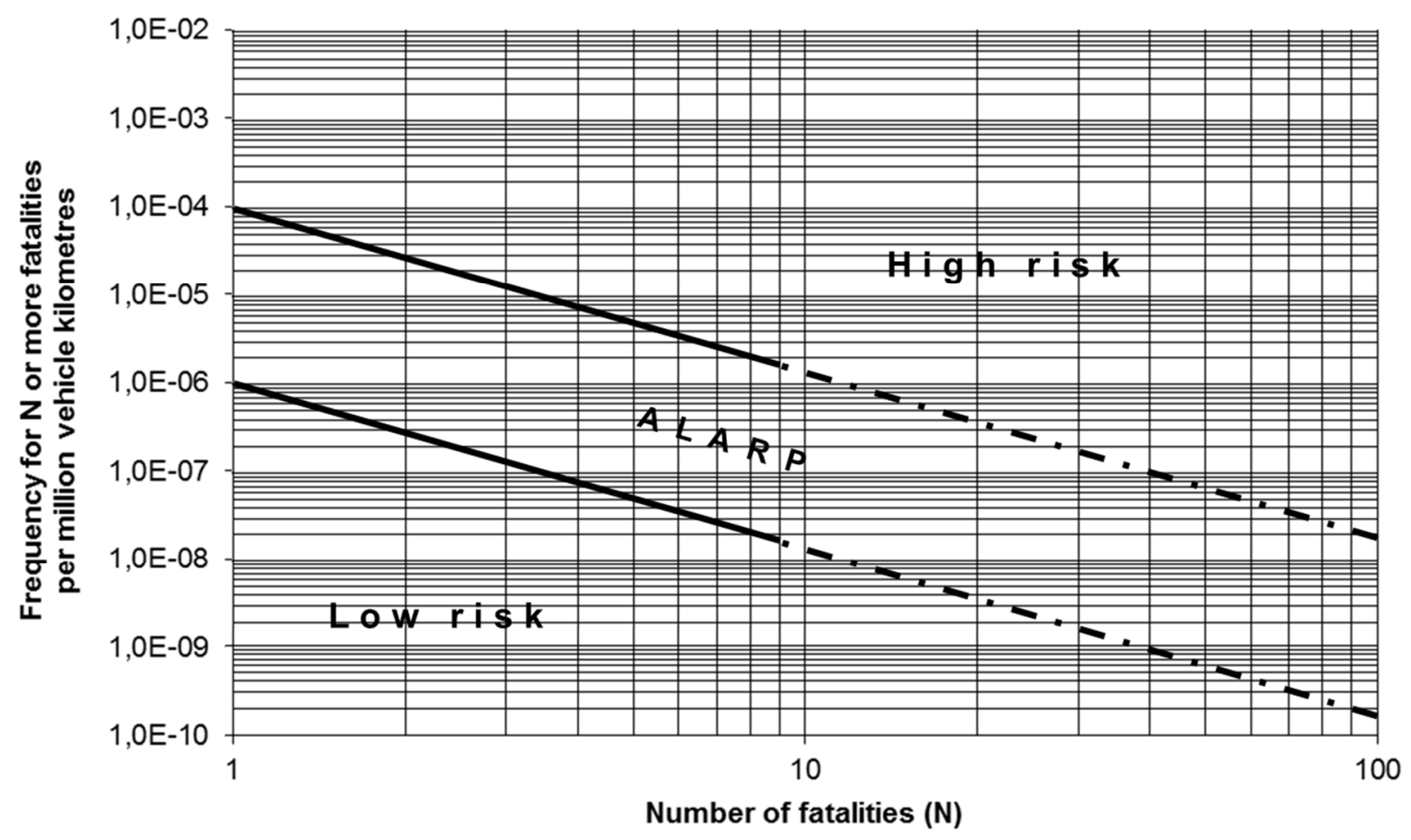

Figure 5. The proposed road tunnel safety target enables individual road tunnel's risk profiles to be plotted in an F/N-diagram and compared to the safety target.

The frequency axis in Figure 5 has been adjusted in order to balance the diagram area and the safety target. Also, the right section of the risk profiles has been dotted in order to outline that it is less certain than the left section. 
Apart from being expressed in an F/N-diagram, the safety target also can be expressed verbally in the following way:

Road traffic by motor vehicles in tunnels per vehicle kilometre should be as safe as surface road traffic by motor vehicles, excluding mopeds.

Apart from providing a quantitative target to be met in existing or new tunnels, the proposal also forms the basis for the safety policy. That, in itself, is no small thing. By example, it may be stated that the safety target indicates:

- That prevention of single-vehicle accidents and collisions in tunnels is good safety policy since it saves lives and reduces the number of accidents that can escalate beyond control.

- That prevention of vehicle-fires and dangerous goods accidents in road traffic in general is good safety policy since it reduces the likelihood of them occurring in tunnels.

- That mitigating measures must be considered if preventive measures fail to meet the safety target, in order to reduce the consequences from the accidents that do occur.

Road traffic safety is, however, not static. It improves, and in Sweden that has been a fact for a long time. Since the road tunnel safety target is built from surface road safety, this means that improvements in the general traffic safety must be reflected in the safety target. Thereby, it is obvious that it has to be revised periodically. From a Vision Zero Initiative perspective that is not odd since it already contains sub-targets that are revised and adjusted to more stringent levels with time. But, before implementation, it may be good advice to check on the durability of the target proposed.

To assess this, the situation in the year 2025 has been tested. The prognoses on accident data and vehicle mileage thereby have been assessed from data covering the years 2003 - 2012. The number of accidents resulting in various numbers of fatalities per year during the period 2015 - 2024 thereby can be estimated to be 195 (1 fatality), 10 (2 fatalities), 2,5 (3 fatalities), 0,2 (4 fatalities), 0,2 (5 fatalities), 0,1 (6 fatalities), 0,05 (7 fatalities), 0,025 (8 fatalities) and 0,025 (9 fatalities). The vehicle mileage has been assessed to amount to about 79000 million vehicle kilometres. The result is presented in Figure 6.

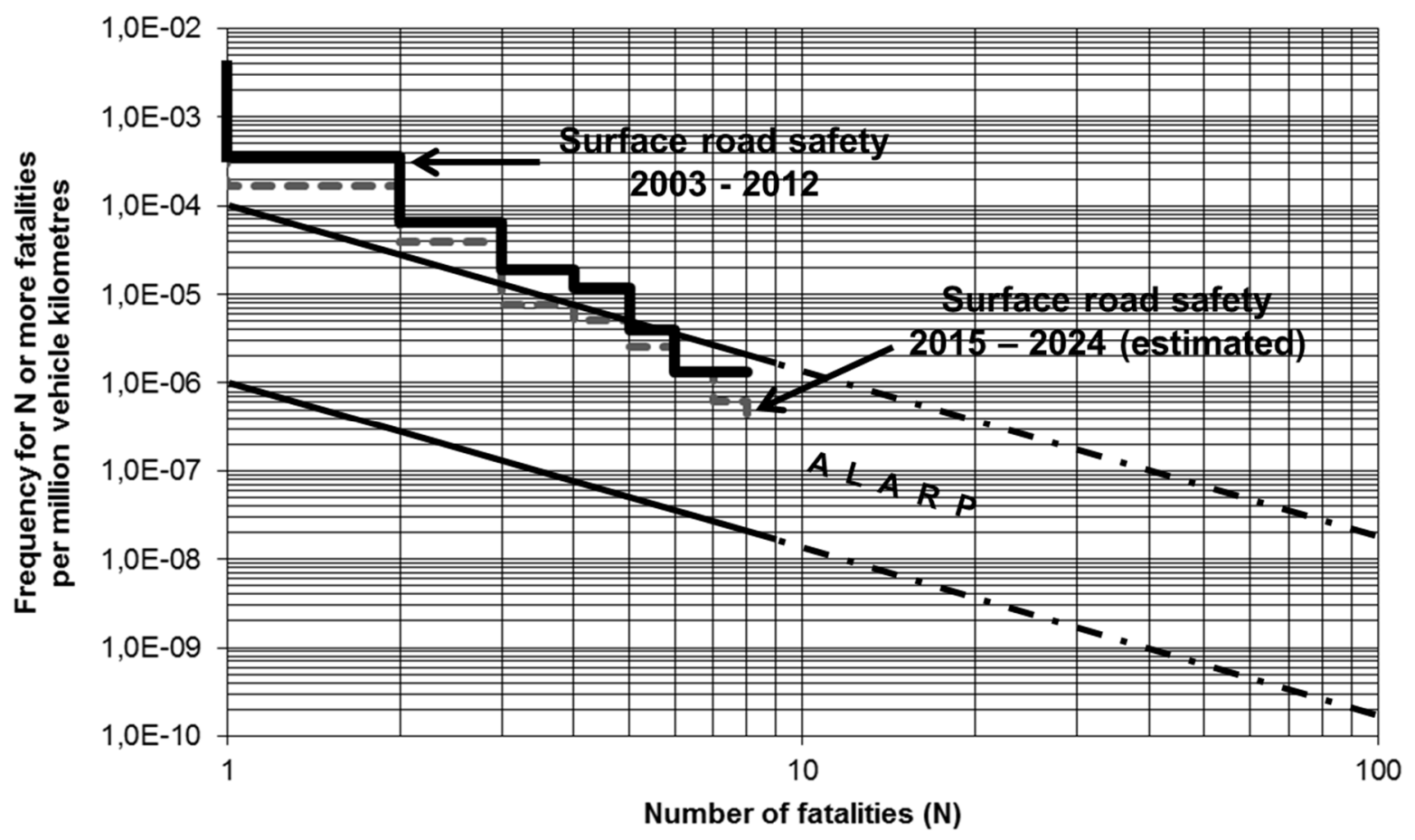

Figure 6. The estimated risk profile for the period 2015 - 2024 compared to the profile for the period 2003 2012. The proposed ALARP area is also outlined.

As expected, a part of the safety target has been consumed by the reduced number of accidents. This is mainly due to the steep reduction of the number of accidents during the start of the founding data period. This trend, however, cannot be seen to last. Instead, the reduction can be appreciated to wear off successively. It, therefore, may be 
realistic to anticipate a first revision of the safety target after $10-15$ years of practice, a period that also may be seen as a test period. After that, the need for revisions will wear off, as do the reduction in number of accidents. Compared to the life-span of other sub-targets within the Vision Zero Initiative, that can be seen as durable enough.

\section{Discussion}

It is important that road travelling can be conducted at a safe-enough level on all parts of the road network, both on surface roads and in tunnels. Present governing documents do not, however, offer any guidance on how safe is safe enough. Thereby, it is not possible to answer the question:

\section{How safe is it to travel through Swedish road tunnels?}

The above implies that the safety level in both existing tunnels and tunnels that are being planned and constructed is unknown. This exposes tunnel planning, design and construction to uncertainties that may lead to tunnels being put into operation with insufficient knowledge of how safe they are. It also indicates that the possibilities to evaluate the utility cost for this unknown safety will be limited. The absence of explicit road tunnel considerations within the Vision Zero Initiative scope also may be problematic since it only takes one, unfortunate, tunnel accident to endanger the national safety target for one year.

Naturally, the comparison with surface road traffic safety may be criticised, primarily because of the analytical twist to equate the likelihood for an initiating event on one vehicle-kilometre of surface road traffic and one vehicle kilometre of road tunnel traffic. It, however, makes analytical sense even if it yet is to be proven and no solid data that points the other way has been found. Also, it may be argued that road tunnels are viewed as "holes in the ground", i.e. stripped from safety measures separating them from surface roads as the safety target is constructed. However, since the target aims to enable road tunnel traffic to be as safe as surface road traffic, the need for safety measures only can be motivated if there is a need for them, identified by the result from a quantitative risk analysis which is compared to the safety target. Some tunnels, therefore, may need a more extensive palette of safety measures, whereas others only may need a minimum of standard measures.

The foremost danger to management by objectives is that the target and its achievement is isolated from the context and that the guiding purpose of the process is lost. A deep understanding of how the target may be met thereby is important, i.e. how the analytical work is being performed and what data and what knowledge it is based upon. Henceforth, decision-making in the future also will have to be based on an understanding of when data provide more or less certain answers and that it is important to take responsibility for both the short term and the long run, to be able to separate the reasonable from the unreasonable and the likely from the unlikely.

In the long run the absence of a quantitative safety target may be difficult to defend. Apart from being evasive of the critical question of how safe it is to travel in road tunnels, it also endangers the credibility of the traffic safety work as a whole. Thereby, it is proposed that the suggested safety target should be considered for national acceptance, following from certain adjustments. The alternative of not having a safety target can be seen as worse from all points of view, although periodical adjustments of the target strictness as traffic safety improves will have to be considered, as with other sub-targets within the Vision Zero Initiative. This can also be seen as a part of a natural knowledge development, as also present work within the Vision Zero Initiative can be characterized in terms of learning. Some allowance for preparatory training may also be seen as natural.

The foremost result from the implementation of the safety target and the analytical methodology will be improved expediency in the traffic safety work. This is due to the need for safety measures to be decided based upon their effect on safety and the actual need to achieve the target. Partly, the safety measures will be directed towards reducing the frequencies of single-vehicle accidents and collisions, fires and dangerous goods accidents. Partly they will be directed towards mitigating the consequences from fires and dangerous goods accidents in the cases where preventive action fail to meet the safety target. In addition, a systematic use of the analytical methodology can be expected to improve the quality in all related decisions. To perform a risk analysis can be seen as a part of what it takes to achieve the safety objective since it provides detailed knowledge regarding the risks of the analysed system. The risks in question therefore will be managed with a strategy that is tailor-made for the nature of the actual risks.

There are several reasons to why systematic risk analyses may be preferred compared to other, more informal or intuitive, ways of handling the extensive, but not complete, available knowledge (Lindberg and Morén, 1994). Primarily it implies the use of risk analytical methodologies, involving systematic collection, organisation and compilation of available knowledge in a way that allows gaps in knowledge to be identified. This enables the prerequisites for the analyses to be tested, questioned and corrected by independent persons or agencies. The methodologies also imply assumptions and assessments that form the base for various estimations to be clarified 
in order to avoid misunderstandings. This enables premises, simplifications and uncertainties stemming from data to be managed transparently and be supported by other approaches. All in all, this improves the quality of the related work.

\section{Conclusions}

It is obvious that without formulating a safety target and adopt a strategy that embraces the whole consequence potential for road tunnels compared to surface roads, the control of personal injury development in the traffic safety work as a whole may be endangered. This problem can be minimized by means of the suggested proposal.

Present governing documents prescribe the performance of risk analyses in various specific cases in order to assess what can be accepted. However, the same documents also fail to address what that is. This can undermine the safety culture and threaten the confidence for the analytical approach. To respond to that, it should be considered to prescribe the regular performance of risk analyses in planning and construction of road tunnels. The prescription of a safety target that quantifies what level of safety that can be accepted in tunnels also should be included in this, by example on a national level. In this paper, such a target is proposed.

The quantitative target for life safety in road tunnels improves the Vision Zero Initiative's position to guide the assessment of safety in road tunnels. The target does not replace the Vision Zero Initiative but complements it, the same way other semi-targets within the Vision's context. The target enables the identification of need for action when that is necessary, but the reverse when safety is adequate. The target also can be adjusted in line with changes in the general road safety. Other advantages are that the question of how safe it is to travel in Swedish road tunnels will be possible to answer, as well as the quality of road tunnel design and safety concepts will improve. This lays the foundation for a range of other improvement opportunities.

The increase in total risk in tunnels compared to surface roads must be compensated if equality in traffic safety is to be achieved. Since the increased risk in tunnels is founded on the view of the tunnel as a road through a "hole in the ground", this compensation may be realized by means of a combination of accident prevention and mitigation measures which:

- Reduces the likelihood for single-vehicle accidents, collisions, fires and dangerous goods accidents.

- Reduces the likelihood for escalation of the accidents that do occur, with regard to single vehicle accidents, collisions, fires and dangerous goods accidents.

The road tunnel safety target enables the identification of the need for complementary safety measures when that is necessary and the opposite when safety is sufficient. The target also is designed to be adjusted in accordance to developments in road traffic safety in general. The safety target does not replace the Vision Zero Initiative, but rather complements its framework regarding road tunnels. Thereby, it can be viewed as any other of present subtargets.

\section{Further Work}

The work for this paper has highlighted several opportunities for improvement that are considered important for the possibilities to achieve a better and clearer control of safety in road tunnels. It is proposed that:

- The issue of safety in tunnels is included within the scope of the present Swedish Vision Zero Initiative work.

- The Safety Indicators in use within the Vision Zero Initiative are extended with road tunnel accidents, vehicle fires and dangerous goods accidents in road traffic.

- Annual reports are compiled from the national accident database regarding road tunnel accidents, accident types, frequency and severity.

- Annual reports are compiled from the database of rescue services regarding response to vehicle fires and dangerous goods accidents in road traffic.

Knowledge of what the proposed safety objective means in practice is however insufficient at present. It is therefore proposed that:

- The safety level is evaluated for one or a few selected case study tunnels to test the methodology. This is proposed to include:

- Calibration of the proposed safety target.

- Assessment of the resulting safety level in tunnels if no safety measures at all are included and, also, evaluation of what level of safety present regulatory framework leads to. 
- Comparison with other countries' national safety targets.

- Evaluation if the proposed safety level is affordable from a total cost perspective.

The next 15 years of road construction in Sweden will double the total road tunnel length compared to the present situation. Therefore this may be the moment to be proactive since road travellers will be increasingly exposed to road tunnel specific risks in the near future. Thereby, in order to be able to look forward towards a sustainable future regarding road traffic safety, it may be good advice to consider revision of the present risk management strategies regarding road tunnels.

\section{References}

2004/54/EC, EU-directive 2004/54/ regarding minimum safety requirements for tunnels in the Trans-European Road Network.

Lindberg, E., \& Morén, B. (1994). Risk analysis method for transportation of dangerous goods on road and rail road. VTI-report 387:1.

Lundin, J. (2019). Quantification of a Safety Target for an Underground CNG Bus Terminal in Stockholm. Fire Safety Journal, 104, 57-66. https://doi.org/10.1016/j.firesaf.2019.01.005

Malmtorp, J., Lundin, J., \& Vedin, P. (2014). Life safety in road tunnels - A safety target proposal. The Swedish Road Transport Administration publ. nbr: 2014:124.

Norwegian Public Road Administration. (2011). Development of a best practice methodology for risk assessment in road tunnels.

PIARC. (2007). Integrated approach to road tunnel safety.

PIARC. (2008). Risk analysis for road tunnels.

PIARC. (2011). Road Tunnels Manual.

PIARC. (2012). Current Practice for risk evaluation for road tunnels.

Slovic, P. (1997). Trust, Emotion, Sex, Politics, and Science: Surveying the Risk Assessment Battlefield. University of Chicago Legal Forum, 1, Article 4.

Strömgren, P., Berg, S., Ekman, A. K., \& Bergström, K. (2014). The accessibility and safety of Swedish tunnels, The Swedish Road Transport Administration, 2014.

Swedish National Board of Building, Housing and Planning. (2005). Risk Analysis Methods - DP 2.2, Life-safety in tunnels.

Swedish Rescue Services Agency. (1997). Evaluation of risk.

Swedish Road Transport Administration. (2004). Design requirements and recommendations for tunnels. Publ,124.

Swedish Transport Agency. (2019). Yearly accident data from 1950, accidents reported by the police. Retrieved from http://www.transportstyrelsen.se

Tingvall, C. (1997). The Zero Vision. In: von Holst H., Nygren Å., Thord R. (eds) Transportation, Traffic Safety and Health. Springer, Berlin, Heidelberg. pp. 37-57. https://doi.org/10.1007/978-3-662-03409-5_4

Transport Analysis in Sweden (Trafikanalys). (2019). Information about the vehicle mileage per year by Swedishregistered cars, lorries, buses and motorcycles in a year.

\section{Copyrights}

Copyright for this article is retained by the author(s), with first publication rights granted to the journal.

This is an open-access article distributed under the terms and conditions of the Creative Commons Attribution license (http://creativecommons.org/licenses/by/4.0/). 